\title{
Evaluation of a Pulse Width Modulated Bypass Nozzle for the Development of a Variable Load Residential Oil Burner
}

\author{
Mebougna L. Drabo', Narinder K. Tutu², Thomas Butcher ${ }^{2}$, George Wei², Rebecca Trojanowski ${ }^{2}$ \\ ${ }^{1}$ Department of Mechanical \& Civil Engineering, and Construction Management, Alabama A \& M University, \\ Normal, AL, USA \\ ${ }^{2}$ Sustainable Energy Technology Department, Brookhaven National Laboratory, Upton, NY, USA \\ Email: mebougna.drabo@aamu.edu
}

How to cite this paper: Drabo, M.L., Tutu, N.K., Butcher, T., Wei, G. and Trojanowski, R. (2018) Evaluation of a Pulse Width Modulated Bypass Nozzle for the Development of a Variable Load Residential Oil Burner. Engineering, 10, 643-654.

https://doi.org/10.4236/eng.2018.1010047

Received: August 29, 2018

Accepted: October 13, 2018

Published: October 16, 2018

Copyright $\odot 2018$ by authors and Scientific Research Publishing Inc. This work is licensed under the Creative Commons Attribution International License (CC BY 4.0).

http://creativecommons.org/licenses/by/4.0/

(c) (i) Open Access

\begin{abstract}
Due to the need for energy conservation in buildings and the simultaneous benefit of cost savings, the development of a low firing rate load modulating residential oil burner is very desirable. One of the two main requirements of such a burner is the development of a burner nozzle that is able to maintain the particle size distribution of the fuel spray in the desirable (small) size range for efficient and stable combustion. The other being the ability to vary the air flow rate and air distribution around the fuel nozzle in the burner for optimal combustion at the current fuel firing rate. In this paper, which deals with the first requirement, we show that by using pulse width modulation in the bypass channel of a commercial off-the-shelf bypass nozzle, this objective can be met. Here we present results of spray patterns and particle size distribution for a range of fuel firing rates. The results show that a desirable fuel spray pattern can be maintained over a fuel firing rate turndown ratio (Maximum Fuel Flow Rate/Minimum Fuel Flow Rate) of 3.7. Thus here we successfully demonstrate the ability to electronically vary the fuel firing rate by more than a factor of 3 while simultaneously maintaining good atomization.
\end{abstract}

\section{Keywords}

Residential Oil Burner, Variable Load, Pulse Width Modulated Burner Nozzle, Bypass Nozzle, Droplet Spray Size Distribution, Variable Fuel Firing Rate

\section{Introduction}

Because of modern energy efficient design, the heating requirements for new 
construction are significantly lower than old residential buildings. Thus a lower firing rate boiler is sufficient to fulfill the peak demand. This is especially true for smaller homes. Secondly, because the heating requirements during a given day continuously change with time due to the changing weather conditions and demand from the occupants, a conventional residential boiler must cycle (on/off) many times during a day. During the starting phase the combustion efficiency of oil burners is much lower than that during the steady state operation; consequently the level of pollutants emitted is higher.

Excessive on/off cycling leads to an overall reduction in the energy efficiency of the heating system and an increase in the environmental pollution contributed by the oil burner. Furthermore, it also results in larger temperature swings within the house. Excessive on/off burner cycling also leads to frequent plugging of the swirl nozzles. A low firing rate load modulating oil burner will not only provide more thermal comfort for the occupants, it will also result in lower fuel costs and a reduction in the pollutant emitted.

Standard pressure swirl nozzles are designed for a constant oil firing rate. If one attempts to lower the oil firing rate by reducing the pump supply pressure, the resulting atomization is poor (larger fuel droplets), thus leading to poor combustion. Bypass pressure swirl nozzles, such as those from Delevan, do allow operation at lower firing rates; but the spray quality (fuel droplet mean size) becomes poor. Therefore the first requirement for the development of a variable firing rate oil burner is a fuel spray nozzle whose fuel firing rate can be turned down (by a factor of two or more) without degrading the fuel droplet mean size.

Krishna et al. [1] were one of the early investigators to demonstrate such a system for residential oil burners. They tested two approaches: a "Valve in Line" and an "Integrated Valve and Nozzle System". In the first method they used a pulse width modulated (PWM) solenoid valve directly upstream of a conventional pressure swirl nozzle to change the fuel firing rate. They demonstrated a fuel flow rate turndown Ratio of about 1.4. However, they observed poor atomization of fuel droplets at low firing rates. They noted that this was due to fact that the fluid pressure in the nozzle did not remain constant due to the pulsating flow. Their pressure measurements showed that the pressure in the fuel line just upstream of the nozzle pulsed from 40 psi to 160 psi at the corresponding PWM frequency. In order to improve their system, they then asked a commercial vendor (Lee Company) to integrate their miniature solenoid valve within the fuel spray nozzle. They reasoned that this would improve atomization since the pressure variation in the fuel line would be substantially reduced due to the significantly reduced fuel volume between the solenoid valve and the spray nozzle. They operated the solenoid valve at $200 \mathrm{~Hz}$, and demonstrated reasonable atomization up to a turndown ratio of about 1.7. However, the volume mean diameters for the "Integrated Valve and Nozzle System" (52 microns to 80 microns) was larger than for the "Valve in Line" (37 microns to 65 microns) system. One major disadvantage of the integrated valve and nozzle system is the cost of such a nozzle (several hundreds of dollars per integrated nozzle). Since nozzle 
must be periodically replaced due to fouling, one is forced to replace the very expensive miniature solenoid valve at the same time.

Kohlmann [2] presented a variable firing rate nozzle that subdivides the fuel output from the fuel pump into two parallel lines via a T-Pipe. One line is directly connected to the nozzle inlet, and the second line is connected to the nozzle inlet via a control valve. When the valve is fully closed the fuel flow rate is the minimum. The fuel flow rate can then be adjusted by opening (or closing) the valve on the second fuel line. They mention that this should not change the fuel pressure, and they argued that the spray cone angle and atomization quality should remain the same. They did not present any pressure measurements or droplet size distribution measurements. However, if it is observed that the fuel firing rate changes with valve position, it does not seem logical that the oil pressure at nozzle inlet should remain the same irrespective of the valve position on the second parallel oil inlet. Clearly, the directly connected fuel line must provide a large pressure drop when the valve is closed on the other line. Otherwise, there is no mechanism for the fuel flow rate to change with valve position.

For the same objective of developing a variable load oil burner, Drabo et al. [3] experimented with the technique of flash atomization to simultaneously achieve reduction in the fuel firing rate and a reduction in the droplet mean diameter. With this technique, which requires heating the fuel to a specific temperature for a given fuel flow rate, they demonstrated a turndown ratio of about 1.5 for the fuel firing rate, and lower droplet mean sizes at lower fuel flow rates. However, there are disadvantages of this technique. Since fouling of fuel spray nozzle exit orifices is common, at higher fuel temperatures this fouling will be accelerated [4]. As pointed out by Olson [4], the rate of gum formation and sludge formation on the nozzle is increased with an increase in nozzle temperature. If the fuel is heated, clearly the nozzle temperature will be higher. The authors also observed this directly during their previous work on flash atomization [3]. This implies increased frequency of nozzle replacements, and hence increased maintenance cost for the user. Secondly, to achieve large reductions in fuel firing rate, the fuel must be heated above the boiling point of the fuel. This can lead to unstable operation and burnout of the nozzle due to choking of the two phase flow through the exit orifice.

Muller et al. [5] report on the difficulty of utilizing conventional swirl nozzles for fuel sprays for low and variable fuel flow rates. They demonstrated a variable low fuel flow rate burner that is based upon a novel atomization concept. It utilizes a droplet generator to create a small diameter cylindrical fuel jet. The jet impinges on a piezo-driven target that serves as a droplet generator. When the piezo-actuator is turned on, it creates fuel droplets, and the droplets are then transported to the burner section via air flow. When the piezo-actuator is turned off, no droplets are created and the liquid fuel falls to the bottom and is returned to the supply vessel. The piezo-actuator is pulse wave modulated to achieve the desirable fuel flow rate.

Here, we are reporting on the results of an alternative approach which is 
closely related to the method used by Krishna et al. [1]. We have used an off-the-shelf bypass nozzle from a commercial vendor; and instead of modulating the fuel flow into the fuel spray nozzle directly, we modulate the bypass flow (via a pulse width modulated solenoid valve) thus changing the actual fuel flow rate through the nozzle exit. The rationale being that the fuel pressure change within the nozzle near exit orifice would not change drastically, and therefore atomization quality is likely to remain about the same. We present the results for the mean droplet size, photographs of fuel spray, and videos of fuel sprays for various fuel flow rates at two fuel temperatures: room temperature and at minimal fuel flashing temperature. Even though we realize practical problems with flashing, we wanted to see if it would be necessary for good atomization at very low fuel flow rates. Additional details of their droplet generator are provided by Etzold et al. [6] who studied and developed this novel atomizer design in which a liquid jet impinges on a flat plate to achieve low firing rates.

\section{Experimental Set up}

The experiments were divided into two parts. The first part consisted of performing droplet size distribution measurements under various operating conditions (PWM duty cycle, PWM frequency, fuel temperature). For these tests we used water as a simulant fuel. Extensive atomization measurements carried out at Brookhaven National Laboratory in the past have shown that there is no significant difference in the droplet size distribution measurements between "water" and "No. 2 heating fuel". Although a variable fuel firing rate spray nozzle is only one requirement for the load varying oil burner, the other being the controllable varying retention head design for the burner to adjust and modulate the air flow around the spray nozzle, we nevertheless also performed combustion tests in a conventional retention head burner to demonstrate at least a stable flame under various fuel firing rates with the pulse wave modulated bypass and a bypass nozzle.

\section{Droplet Size Measurements}

A schematic of the experimental setup for droplet size distribution measurements is shown in Figure 1. Water, which is used as a fuel simulant, is injected at $100 \mathrm{psi}$ into the bypass nozzle. The nozzle holder and the fuel line leading to it are heated and maintained at the desired temperature via a combination of a variac and a temperature controller. As shown in Figure 1, a manual flow control valve followed by a PWM solenoid valve in is connected to the bypass line of the bypass nozzle. This proved necessary because without the manual valve, the fuel flow rate through the nozzle is just too small for atomization to occur at $100 \%$ PWM duty cycle. Thus this setting is set for the minimum fuel flow rate for the nozzle. Once set, then only the PWM duty cycle is used to change the fuel flow rate through the spray nozzle. A cross section of the Delevan bypass nozzle used for these tests may be seen in the vendor's document located at: http://www.delavaninc.com/pdf/variflo_catalog.pdf. 
The solenoid valve discharges the bypassed water back into the water supply tank that is mounted on an electronic scale. A video of a stop watch and the scale front panel are recorded during the particle droplet size measurement period for the purpose of computing the net fuel flow rate through the spray nozzle. For these tests an RC SL4-205 gasoline fuel injector was used as Solenoid Valve for Bypass Flow Control.

A Malvern Spraytec System, which is a laser diffraction based instrument, was used to measure the droplet size distribution within the liquid spray at various liquid temperatures. This system has a particle detection range of $0.1 \mu \mathrm{m}$ to 900 $\mu \mathrm{m}$. Additional details for this system are provided in Reference [2].

\section{Results and Discussion}

\subsection{Droplet Size Distribution Measurements}

The variation of water flow rate through the nozzle as a function of PWM duty cycle at two different water temperatures is shown in Figure 2. A comparison of the flow rates at two different PWM frequencies $(10 \mathrm{~Hz}$ and $20 \mathrm{~Hz})$ is also shown in Figure 3. Droplet size distributions were measured and recorded for all these operating conditions. As can be seen, a maximum turndown ratio of 3.7 was achieved for the flow rate through the nozzle. Sensitivity of flow rate to the PWM frequency is clearly observed. Also, most of the flow rate variation occurs between $0 \%$ and $50 \%$ duty cycle.

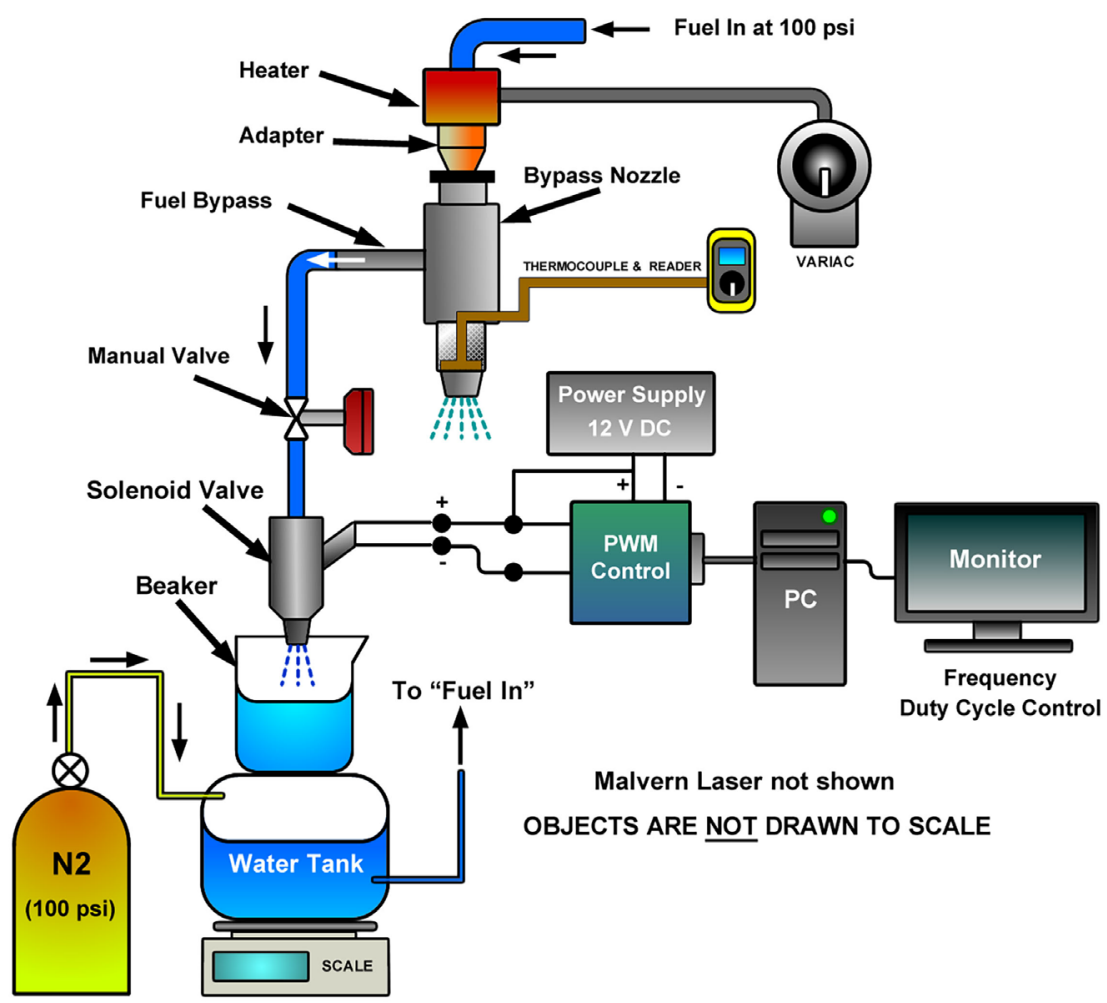

Figure 1. Schematic layout of the Droplet Spray Measurement Setup. Malvern Spraytec System not shown for clarity. 


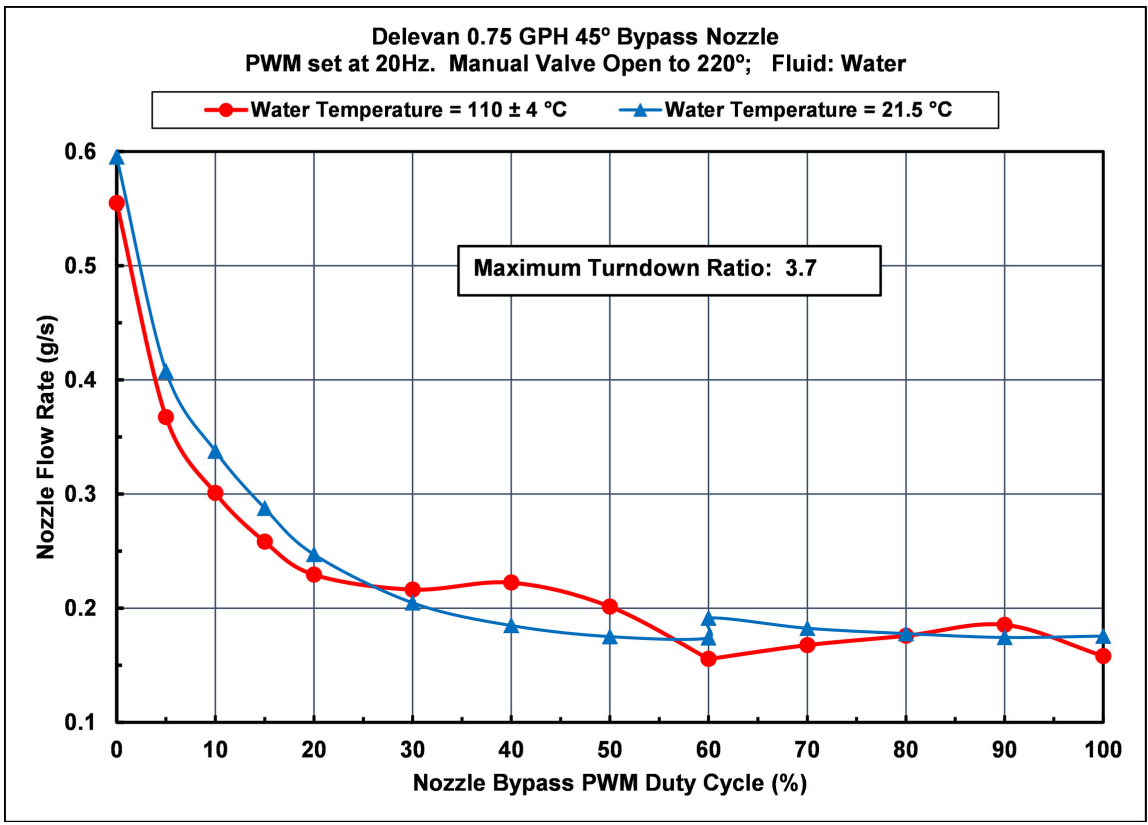

Figure 2. Variation of nozzle flow rate with PWM Duty Cycle operated at $20 \mathrm{HZ}$.

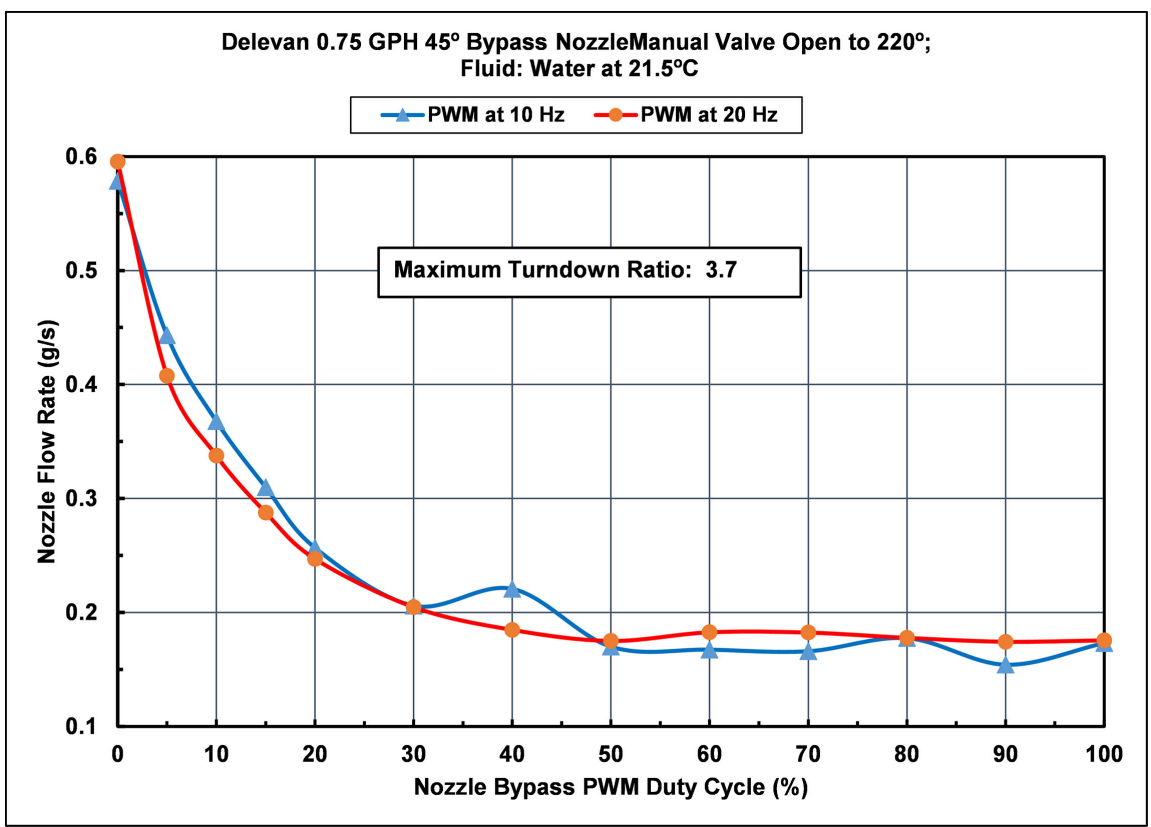

Figure 3. Comparison of nozzle flow rate with PWM frequencies of $10 \mathrm{~Hz}$ and $20 \mathrm{~Hz}$.

Figure 4 shows the measured Sauter mean diameter (D $[3,2])$ within the droplet spray for various nozzle flow rates. These measurements represent sample averages recorded over a time interval of 60 seconds or more. First, as is well known and expected $[5,3]$, the mean diameters are smaller at $110^{\circ} \mathrm{C}$ than at room temperature. As the water temperature goes up, its absolute viscosity goes down, which leads to the lower water flow rate (due to swirling flow in the internal nozzle slots [7]) and hence smaller thickness of the conical sheet at the exit orifice of the nozzle, thus leading to smaller droplets. Also, at $110^{\circ} \mathrm{C}$ some 
flashing (from liquid to vapor) of water may result in further reduction in droplet sizes. Also, the results show that the mean droplet size is actually smaller at lower flow rates at room temperature fuel. We also see that at very low fuel flow rates, there is very little advantage to be gained by heating the fuel since the droplet mean sizes are not very different at room temperature and at minimally flashing temperature. The data demonstrates good atomization properties of the droplet spray over a maximum fuel flow rate turndown ratio of about 3.7, thus indicating suitability of such a system for a variable fuel flow rate oil burner.

The measured volume averaged mean diameters ( $D[4,3])$ for the corresponding (Figure 4) flow rates are shown in Figure 5. Again, we observe similar behavior to the measured Sauter mean diameters. At $110^{\circ} \mathrm{C}$ droplet sizes are smaller (than at room temperature for maximum flow rate) at all flow rates, and at room temperature atomization is even better (smaller droplet sizes) at low fuel flow rates.

During the droplet size measurement experiments we also recorded videos of the nozzle spray for various duty cycles immediately after recording the Malvern droplet size distribution. A cell phone video camera with macro lens attachment was used for this purpose together with a stroboscope for backlighting the spray. The stroboscope frequency was adjusted so as to match (as closely as possible) the framing rate of the video camera during filming. Stills from these videos are presented in Figures 6-8. A web link for viewing the videos for these conditions is given: https://1drv.ms/f/s!AhL6U6Talgxmkyvkle579VPHUOis.

From these figures and videos we see that the spray is much finer at higher water temperature. Also, at the lower duty cycle of $40 \%$, the spray is fine. In fact we see that the conical film sheet is breaking up early. We also note from Figure 2 that at this operating condition of $40 \%$ PWM duty cycle, the nozzle flow rate is already close to minimum. Thus a much wider cone angle for the spray at $100 \%$ duty cycle (for room temperature water) in Figure 8 is not of much practical consequence.

\subsection{Oil Burner Flame Visualization Tests with the Bypass Nozzle}

A variable firing rate spray nozzle is only one requirement for a load modulating oil burner. Clearly, not only must the mass flow rate of air going through the burner be regulated to match the fuel flow rate, the velocity distribution of air going through and around the fuel spray must be changed as well to maintain a stable flame and combustion quality (low emissions of soot and pollutants). Conventional residential oil burners only have very limited controls for adjusting the air flow rate. These provide a crude and limited control for the air inlet area to adjust the air mass flow rate going through the oil burner. As shown in Figure 9, the only other control for adjusting the air flow rate is the "annular gap" between the swirler and the retention head inside diameter (by moving the nozzle and swirler assembly in the axial direction). Clearly these controls are not 
enough for a load regulating oil burner which is to have the capability of changing fuel flow rate by a factor of two or more. The central swirl flow (velocity distribution) must also be changed. Furthermore these controls must be finer and electronically controlled. For these reasons it is to be expected that a conventional residential oil burner with an installed PWM controlled bypass nozzle is not a suitable candidate for testing the combustion performance.

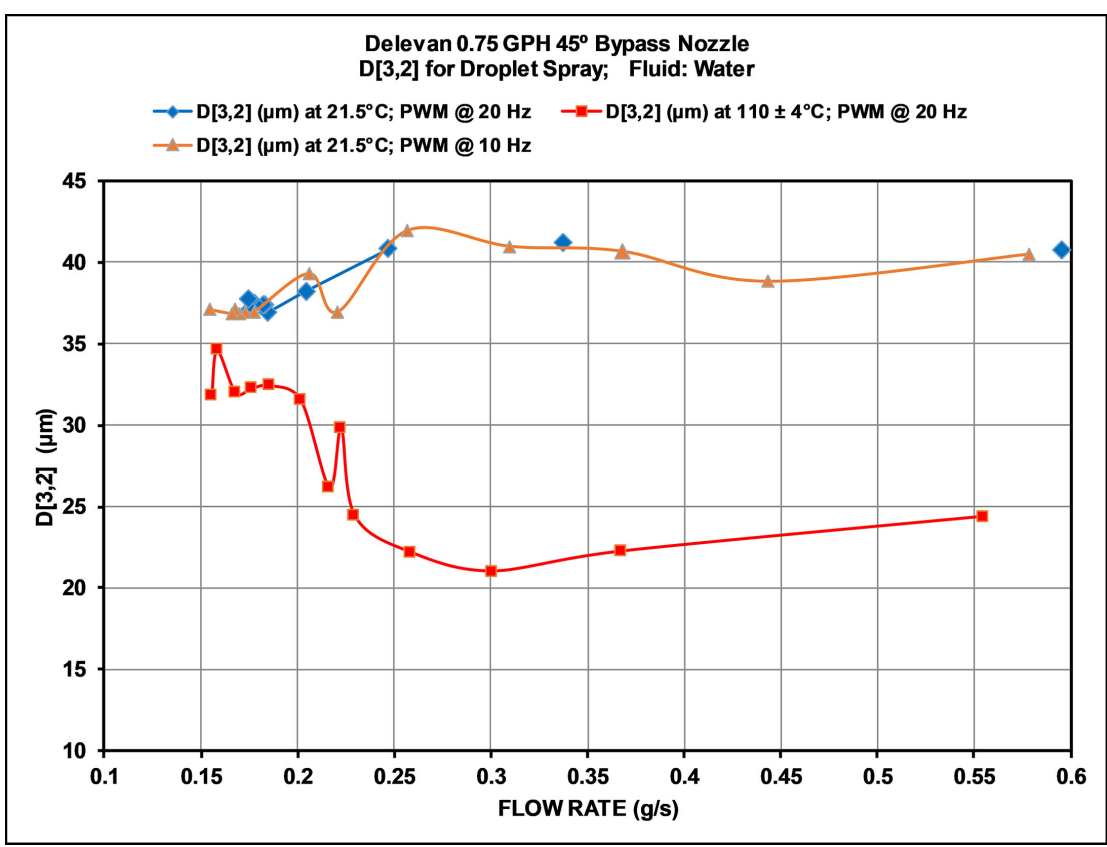

Figure 4. Surface area averaged (Sauter) mean droplet size as a function of nozzle flow rate (Note: $1 \mathrm{~g} / \mathrm{s}=1.133 \mathrm{GPH}$ ).

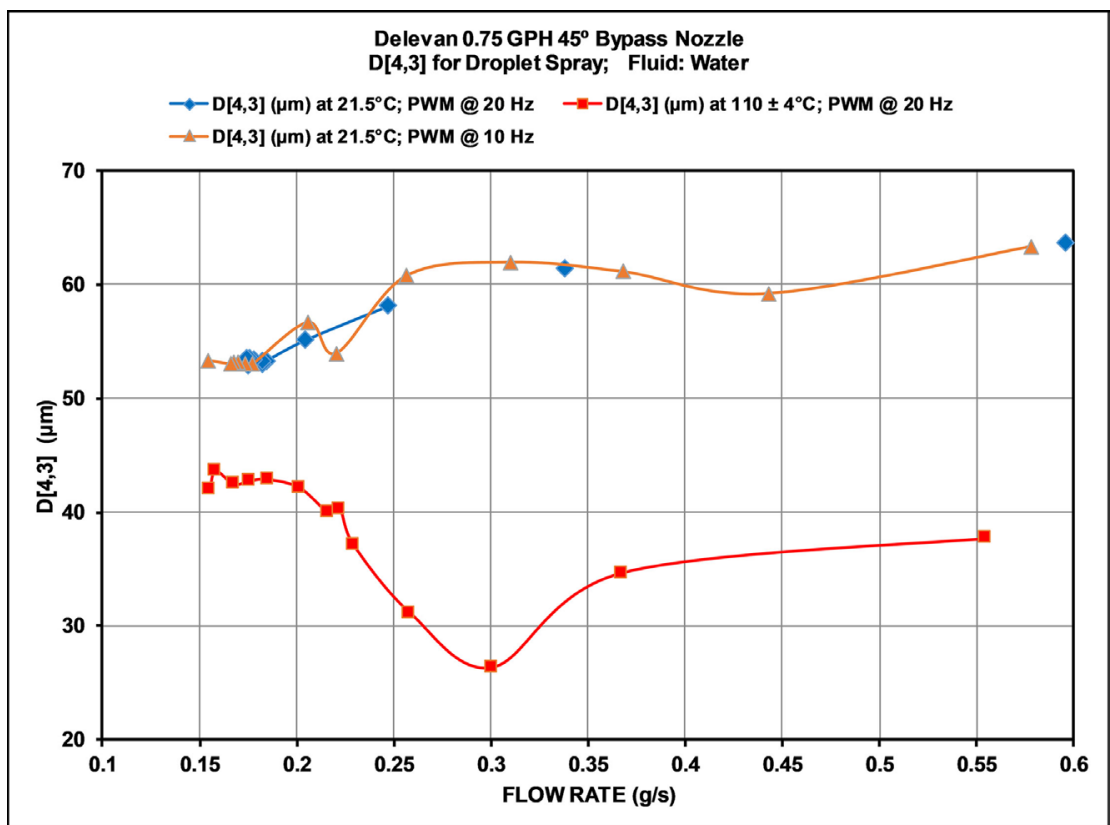

Figure 5. Volume averaged mean droplet size as a function of nozzle flow rate (Note: $1 \mathrm{~g} / \mathrm{s}=1.133 \mathrm{GHP})$. 


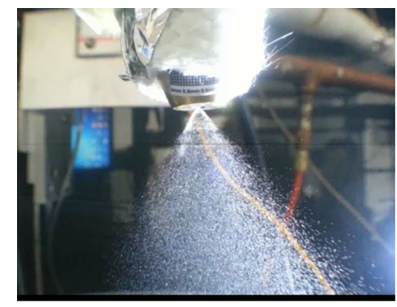

$0 \%$ Duty Cycle $; 21.5^{\circ} \mathrm{C}$

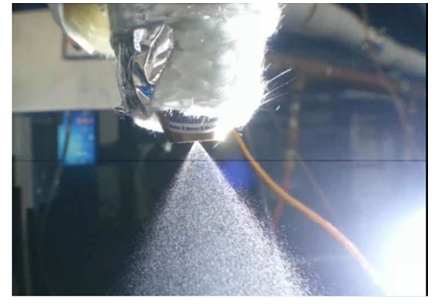

$0 \%$ Duty Cycle; $113^{\circ} \mathrm{C}$

Figure 6. Photograph of the droplet sprays at two water temperatures for maximum flow rate ( $0 \%$ duty cycle for the bypass flow).

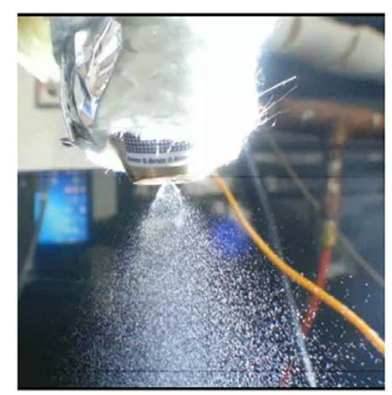

$40 \%$ Duty Cycle; $21.5^{\circ} \mathrm{C}$

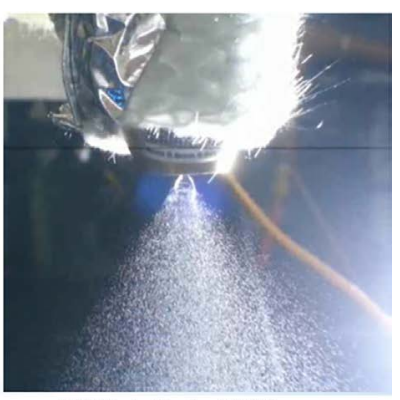

$50 \%$ Duty Cycle; $107^{\circ} \mathrm{C}$

Figure 7. Photograph of the droplet sprays at two water temperatures for intermediate duty cycle for bypass flow.

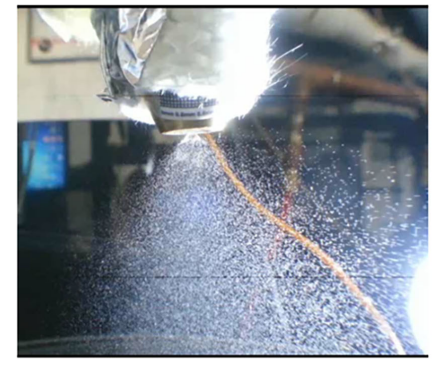

$100 \%$ Duty Cycle; $21.5^{\circ} \mathrm{C}$

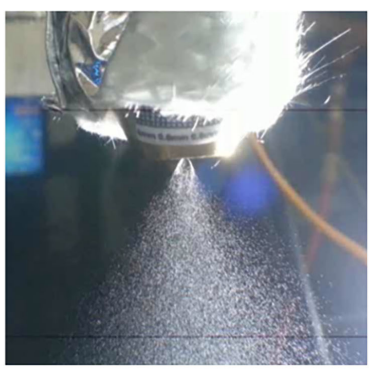

$90 \%$ Duty Cycle; $108^{\circ} \mathrm{C}$

Figure 8. Photograph of the droplet sprays at two water temperatures minimum flow rate.

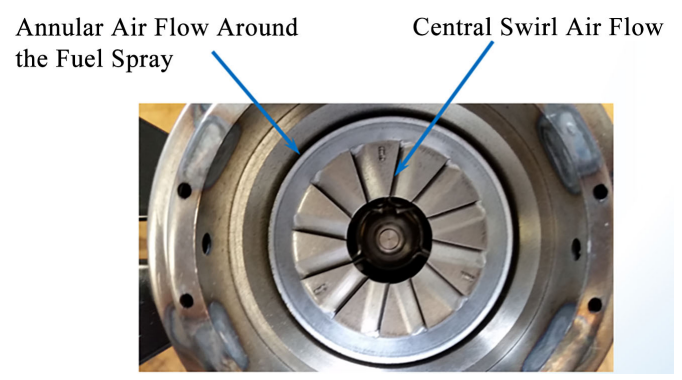

Figure 9. A photograph of an installed oil spray nozzle in the Retention Head of a commercial residential oil burner.

Nevertheless, we did want to demonstrate and verify that we could at least get a stable flame by using an off-the-shelf bypass nozzle at very low fuel firing rates. Due to logistical and time constraints the combustion tests needed to be per- 
formed at a separate location while the droplet size distribution measurements were still in progress. As a result, these combustion tests could not be performed using the pulse wave modulated bypass nozzle. Therefore, for these tests we only used the manual control valve on the bypass line to control the fuel firing rate. Since atomization is expected to be only better with PWM control, these tests are conservative.

A schematic of the experimental setup for flame visualization tests is shown in Figure 10. A Carlin burner with an installed Delevan bypass nozzle is attached to a quartz chamber (instead of a boiler) for the purpose of flame visualization. These tests were run at 100 psi fuel pressure using No. 2 heating oil. The variation of fuel flow rates achieved during these tests is shown in Figure 11. As can be seen, we demonstrated a fuel flow rate turndown ratio of 3.2. Photographs of the flames at two fuel flow rates are shown in Figure 12. The differences in flame character at the two fuel flow rates can clearly be observed. The burner was not obviously setup for proper combustion; but our objective at this time was merely to demonstrate a stable flame at low fuel flow rates.

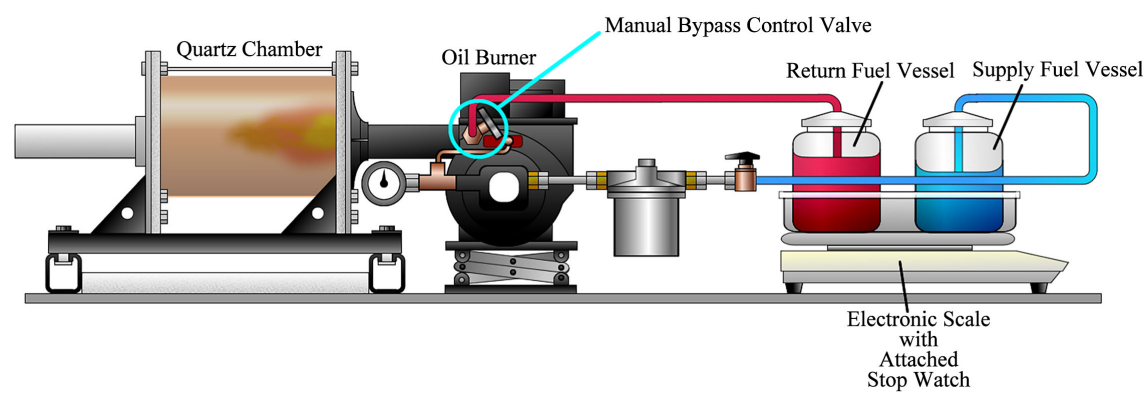

Figure 10. Schematic of the test setup for flame visualization at various fuel flow rates while using the bypass nozzle with manual valve for bypass flow control.

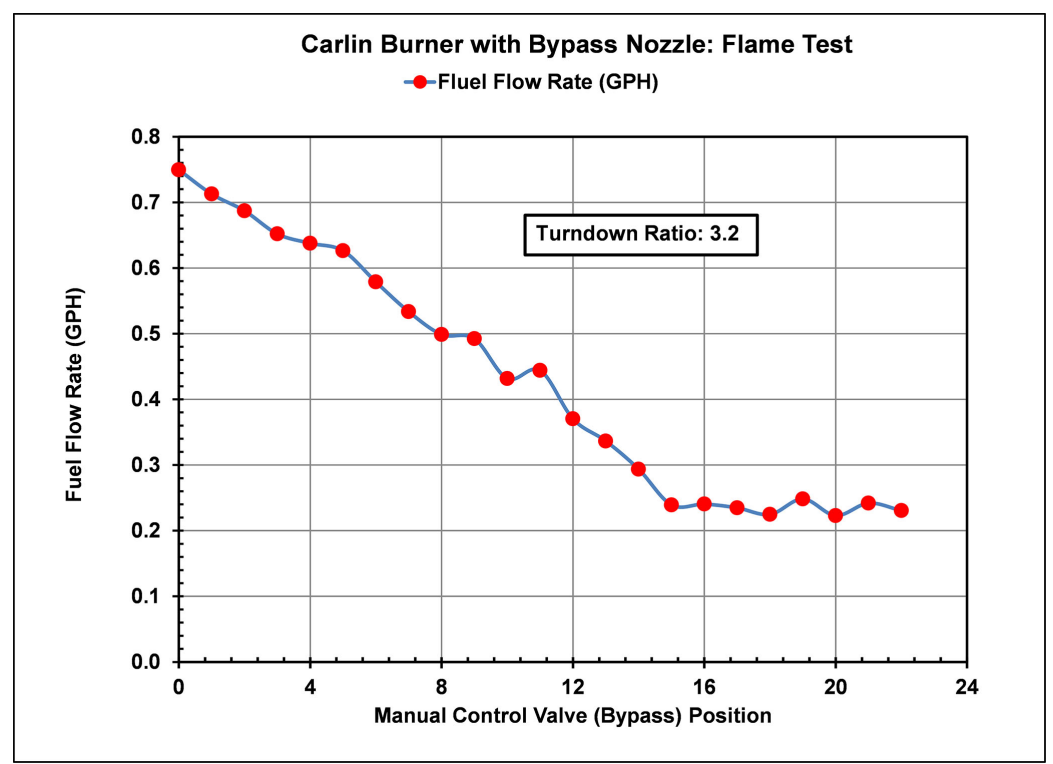

Figure 11. Variation of No. 2 heating oil flow rate during combustion tests as a function of manual bypass control valve position. At position 0 , the bypass is fully closed. 


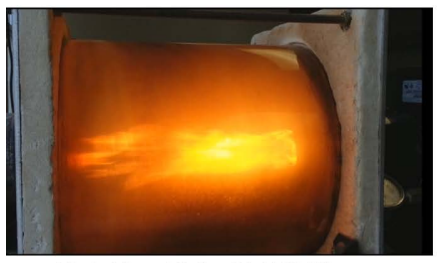

High Flow Rate: $0.75 \mathrm{GPH}$

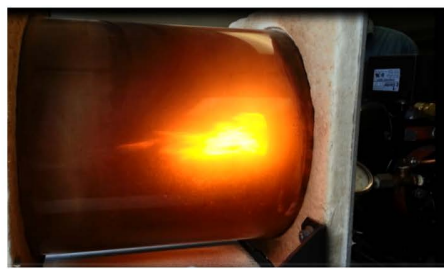

Low Flow Rate: $0.242 \mathrm{GPH}$

Figure 12. Photographs of the flame in the quartz flame chamber at maximum and minimum fuel flow rates.

\section{Conclusion and Suggested Future Work}

We performed droplet size distribution measurements of fuel sprays (with water as the fuel simulant) at various fuel firing rates by controlling the fuel flow rate via pulse width modulated bypass flow from an off-the-shelf bypass nozzle. The results show good atomization properties of the spray over a 3.7 to 1 fuel flow rate ratio. Even though the droplet mean size is lower at higher (minimally flashing) fuel temperature, at lower flow rates the difference is not much. Thus heating of the fuel to high temperature to achieve very low fuel firing rates may not be necessary. Combustion tests with a conventional burner (with crude and un-optimized air flow distribution) also demonstrated a stable flame over a wide range of fuel flow rates. The next logical step towards completing the development of a variable load residential oil burner is to design such an oil burner with dynamically controllable air mass flow rate and velocity profile (in and around the droplet spray). This may require a controllable swirler in front of the spray nozzle and/or retention head. Modified design of the flame tube may also be required. Computational Fluid Dynamics (CFD) simulations should prove to be an important tool for arriving at suitable design options for this.

\section{Acknowledgements}

The authors would like to thank Dr. C. R. Krishna, Yusuf Celebi and Mr. Bennie Mwiinga for their assistance in the laboratory throughout this project. They would also like to thank the Alabama Louis Stokes Alliance for Minorities Participation (ALSAMP) for their support during this project. This project was supported in part by the National Science Foundation-College Research Teams Program (NSF-CRTP) and in part by National Oilheat Research Alliance (NORA).

\section{Conflicts of Interest}

The authors declare no conflicts of interest regarding the publication of this paper.

\section{References}

[1] Krishna, C.R., Butcher, T.A. and Kamath, B.R. (2004) Variable Firing Rate Qil Burner Using Pulse Fuel Flow Control. Report \# BNL-73723-2005-IR, Brookhaven National Laboratory, Upton, NY. 
[2] Juergen, K. (2002) Description of a New Nozzle for Variable Firing Rates. Proceedings of the 2002 National Oilheat Research Alliance Technology Symposium, Providence, RI, 20-21 August 2002, 183-187.

[3] Drabo, M., Tutu, N., Butcher, T. and Trojanowski, R. (2016) Some Results of Flash Atomization in a Pressure Swirl Nozzle. International Journal of Modern Engineering, 16, 44-48.

[4] Olson, E.O. Fuel Nozzles for Oil Burners, Technical Aspects of Applications. Delavan Fuel Metering Products Operation, 11 p. http://beckwithheating.com/ebook/Boiler111/Fuel_Nozzles_for_Burners.PDF

[5] Müller, T., et al. (2018) A Low Power Liquid Fueled Burner Using a Novel Atomization Concept. Joint Meeting, the German and Italian Sections of the Combustion Institute, Sorrento, Italy.

[6] Etzold, M., Han, Y. and Durst, F. (2016) A Novel Spray Generator for Low-Energy Oil Burners. International Journal of Spray and Combustion Dynamics, 8, 53-64. https://doi.org/10.1177/1756827715627065

[7] NORA (2016) Chapter 5: Nozzles and Combustion Chambers. NORA Silver Oilheat Technicians Manual.

https://noraweb.org/wp-content/uploads/2016/10/NORA-Silver-Chapter-5.pdf 